\title{
What happens to the manuscripts that have not been accepted for publication in Occupational and Environmental Medicine?
}

\author{
B Nemery
}

\begin{abstract}
Objectives-To evaluate the fate of manuscripts rejected by Occupational and Environmental Medicine (OEM). Methods-A Medline search was conducted, up to March 2001, to find out whether and where articles submitted to $O E M$ in 1995, 1996, and 1997, but not accepted for publication, were published. The articles were matched by authors and title, sometimes using the abstract to help decide whether the published article was the one that had been previously submitted to $O E M$.

Results-Out of 405 manuscripts rejected (44\% of those submitted), 218 articles $(54 \%)$ were traced in 72 different journals, with more than half being published in seven other major journals dealing with occupational and environmental health (rather than in specialty journals). Most papers were published within 2 years of their initial submission to $O E M$. Only a small proportion $(10 \%)$ were published in a journal with a higher impact factor than OEM (1.96 in 1999).

Conclusion-More than half the articles rejected by $O E M$ found their way into the scientific literature covered by Medline. This figure is comparable with the few available data from other journals. It would be interesting to know the fate of articles published by $O E M$ before they were submitted to our journal. (Occup Environ Med 2001;58:604-607)
\end{abstract}

Keywords: journalology; bibliometry; impact factor

It is commonly considered that when a paper has been rejected by a scientific journal it will ultimately be published in another journal. Ideally, an improved version of the article is published thanks to the comments made by the reviewers, but it is a common experience of authors, reviewers, and editors that this is not always the case. The issue of the effectiveness, and fairness, of the editorial peer review process has been much debated. We do not consider this subject here, but a related issue that should be of interest to those publishing in the area of occupational and environmental health, namely the fate of papers that have been rejected by Occupational and Environmental Medicine $(O E M)$. This analysis was done by performing a Medline search to find out whether and where these manuscripts were eventually published.

\section{Methods}

A list of the manuscripts rejected in 1995, 1996, and 1997 was provided to me by the editorial office of OEM. This list contained the manuscript number, the title and the authors (name and initials), but not their affiliation or country of origin. Each article was searched using Medline (PubMed at http:// www.ncbi.nlm.nih.gov). The search was complete up to the end of March of 2001. Obviously, the search was limited to papers published from the year of submission onwards. In general, articles were readily found by searching by the first author and papers with titles that were identical or reasonably similar to the title of the manuscript submitted to $O E M$ were retained. When no corresponding article was found or-for example, if the first author had a very common name (Smith or Chang) - alternative strategies were used, such as searching by the last author or another author, or by author and one of the keyterms in the title. The abstracts of all possibly matching articles were printed and checked for consistency with the original title and authors. In a few cases, where the title and the authors had changed considerably, some judgment had to be used to conclude that the published article was presumably the one that had originally been submitted to OEM, but this was not thoroughly checked.

\section{Results}

Table 1 shows that half of the articles that had been rejected in 1995, 1996, or 1997, could be traced in the Medline database. There was no major difference among the 3 years in the proportion of papers that were eventually published.

Half of the articles (114 or $52 \%$ ) had a title that was identical or almost identical to that of the version submitted to $O E M$. There were substantial or major modifications of the title in 
Table 1 Yearly distribution of articles submitted to and rejected by OEM, and articles eventually published elsewhere, as found in Medline

\begin{tabular}{llll}
\hline $\begin{array}{l}\text { Year submitted to } \\
\text { OEM }\end{array}$ & $\begin{array}{l}\text { Total submitted } \\
n\end{array}$ & $\begin{array}{l}\text { Rejected } \\
n \text { (\% of submitted) }\end{array}$ & $\begin{array}{l}\text { Published elsewhere } \\
n \text { (\% of rejected) }\end{array}$ \\
\hline 1995 & 315 & $133(42)$ & $76(57)$ \\
1996 & 310 & $141(46)$ & $73(52)$ \\
1997 & 302 & $131(43)$ & $65(53)$ \\
$1995-7$ & 927 & $405(44)$ & $218(54)$ \\
\hline
\end{tabular}

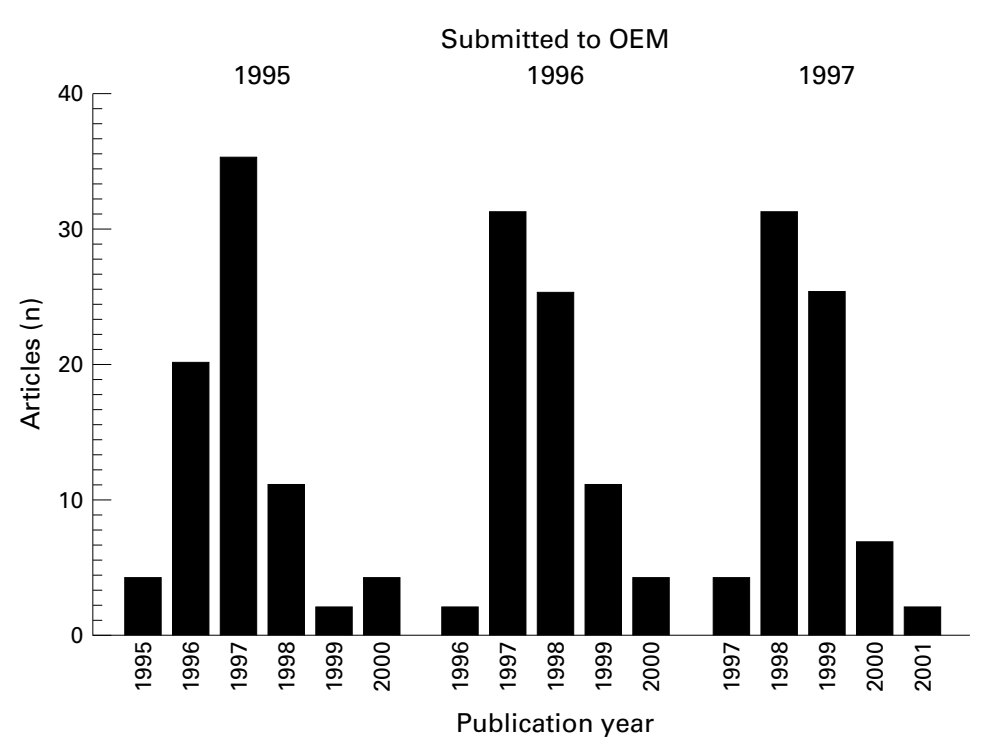

Figure 1 Yearly distribution of publication of articles rejected by OEM.

$74(34 \%)$ and $30(14 \%)$ instances, respectively. The number or order of the authors had been changed for $51(23 \%)$ of the articles.

Most articles were published within 2 years of their submission to and rejection by $O E M$ (fig 1). Very few papers seem to be published later than 3 years after their rejection. Ten articles $(<5 \%)$ were published in the same year as that of their submission to $O E M$; in between three and five instances this could represent attempts of duplicate publication, generally in another language; in two instances it is conceivable that the published papers were conference proceedings in Industrial Health.

Table 2 lists the journals in which the rejected papers were eventually published. The journals are ranked in descending order of number of papers published, then in descending order of impact factor (Fournal Citation Reports: science edition 1999 , as found in http://jcrweb.com), and then in alphabetical order. The impact factor is one of several variables that characterise the way a journal receives citations to its articles over time. It is defined by the Institute for Scientific Information as the number of times a journal was cited within 2 years divided by the total number of articles published by the journal during these same years. The 218 articles were published in 75 different journals. More than half the articles ( 115 or $53 \%$ ) were published in the seven journals that published 10 or more papers. As expected, all these journals are devoted to general occupational and environmental health. The most popular journal is the American Fournal of Industrial Medicine, with 30 papers $(14 \%)$.
Six articles which had been initially rejected by $O E M$, were eventually published in $O E M$ after resubmission as new manuscripts. Seventeen journals published between two and five papers, totalling 44 articles $(20 \%)$. In this category, 10 journals are devoted to occupational or environmental health, including epidemiology and public health, and seven are specialist journals (three in respiratory medicine, three in toxicology, and Bioelectromagnetics).

The remainder of the rejected papers were published in 50 different journals. These include 12 journals within the broad category of occupation, environment, epidemiology, or public health, 33 specialist journals (including nine in toxicology and laboratory sciences, five in respiratory medicine or allergy, four in cancer, three in surgery, two in dermatology), and five general medical journals, mostly of a local distribution.

The vast majority $(90 \%)$ of articles were eventually published in journals with an impact factor smaller than that of OEM. It should be noted that the impact factors used here are the figures for 1999 and not those of the year when the articles had been rejected, but these impact factors and their relative positions within a same category do not change very much over the years. Only $16(7 \%)$ of the articles rejected by $O E M$ were eventually published in a journal with a higher impact factor than OEM; most (11) of these were published in specialist journals (eight in respiratory medicine or allergy) and five were published in Environmental Health Perspectives or the Fournal of Toxicology and Environmental Health. One of the articles published in a more highly rated journal may have been an attempt at duplicate publication, as the published paper was published in the same year as its submission to OEM. In at least one other instance, the published paper was possibly very different from the rejected paper, as its title and the coauthors differed substantially.

Twenty two (10\%) articles were eventually published in a journal that is not listed in the fournal Citation Reports, including five in the International fournal of Occupational and Environmental Health. Only four of the retrieved articles were published in a language other than English, and on the basis of the publication dates it is likely that two of those had in fact already been submitted to these national journals before being sent to $O E M$.

Table 3 shows the geographical distribution of authors (as indicated in Medline abstract) for the seven journals with at least 10 articles.

\section{Comments}

This quantitative evaluation of the editorial fate of the articles that were rejected by $O E M$ over a period of 3 years has by and large confirmed by objective means what could be suspected on the basis of experience with publishing and reviewing articles in the field of occupational and environmental health. Half of the articles (52\%) rejected from OEM ultimately found their way into the scientific literature that is covered by Medline. This proportion is lower than the $69 \%$ reported recently 
Table 2 fournals in which articles rejected by OEM were eventually published

\begin{tabular}{|c|c|c|}
\hline fournal & $\begin{array}{l}\text { Impact factor } \\
\text { (fournal Citation } \\
\text { Reports 1999) }\end{array}$ & $\begin{array}{l}\text { Published papers } \\
\text { (\% of total traced) }\end{array}$ \\
\hline Am f Ind Med & 1.368 & $30(14)$ \\
\hline Int Arch Occup Environ Health & 1.167 & $20(9)$ \\
\hline Occup Med & 0.462 & $15(7)$ \\
\hline Scand $\mathcal{f}$ Work Environ Health & 1.756 & $14(7)$ \\
\hline f Occup Environ Med & 1.477 & $14(7)$ \\
\hline Arch Environ Health & 1.308 & $12(6)$ \\
\hline Ind Health & 0.651 & $10(5)$ \\
\hline Occup Environ Med & 1.958 & 6 \\
\hline Ann Occup Hyg & 1.577 & 5 \\
\hline Int $\mathcal{F}$ Occup Environ Health & - & 5 \\
\hline Sci Total Environ & 1.126 & 4 \\
\hline Hum Exp Toxicol & 1.063 & 4 \\
\hline Environ Health Perspect & 2.469 & 3 \\
\hline Chest & 2.410 & 3 \\
\hline Am $\mathcal{F}$ Respir Crit Care Med & 5.491 & 2 \\
\hline f Toxicol Environ Health & 2.349 & 2 \\
\hline Eur Respir f & 2.334 & 2 \\
\hline Bioelectromagnetics & 1.919 & 2 \\
\hline f Toxicol Clin Toxicol & 1.732 & 2 \\
\hline Environ Res & 1.617 & 2 \\
\hline Neurotoxicology & 1.282 & 2 \\
\hline $\mathcal{F}$ Expo Anal Environ Epidemiol & 0.853 & 2 \\
\hline Eur $\mathcal{F}$ Epidemiol & 0.762 & 2 \\
\hline Public Health & 0.509 & 2 \\
\hline Med Lav & - & 2 \\
\hline Pain & 4.020 & 1 \\
\hline Clin Exp Allergy & 2.702 & 1 \\
\hline Free Rad Res & 2.27 & 1 \\
\hline fpn f Cancer Res & 2.117 & 1 \\
\hline Lung & 1.925 & 1 \\
\hline Ann Epidemiol & 1.862 & 1 \\
\hline Toxicol Sci & 1.778 & 1 \\
\hline Arch Toxicol & 1.683 & 1 \\
\hline Int $\mathcal{F}$ Tuberc Lung Dis & 1.628 & 1 \\
\hline Regul Toxicol Pharmacol & 1.530 & 1 \\
\hline Arch Pathol Lab Med & 1.417 & 1 \\
\hline Eur Neurol & 1.379 & 1 \\
\hline Xenobiotica & 1.335 & 1 \\
\hline $\mathrm{Br} \mathcal{F}$ Urol & 1.282 & 1 \\
\hline Chemosphere & 1.255 & 1 \\
\hline Health Phys & 1.246 & 1 \\
\hline Arch Environ Contam Toxicol & 1.173 & 1 \\
\hline Leuk Res & 1.142 & 1 \\
\hline Teratog Carcinog Mutagen & 1.018 & 1 \\
\hline Dermatology & 0.959 & 1 \\
\hline Cancer Detect Prev & 0.927 & 1 \\
\hline Hematol Cell Ther & 0.907 & 1 \\
\hline Brf Med Psychol & 0.881 & 1 \\
\hline Am Ind Hyg Assoc $\mathcal{F}$ & 0.862 & 1 \\
\hline Contact Dermatitis & 0.741 & 1 \\
\hline South Med J & 0.737 & 1 \\
\hline Eur $\mathcal{F}$ Surg Suppl & 0.687 & 1 \\
\hline Respiration & 0.587 & 1 \\
\hline Aviat Space Environ Med & 0.536 & 1 \\
\hline Physiol Res & 0.521 & 1 \\
\hline Rev Epidemiol Santé Publique & 0.458 & 1 \\
\hline Scand Audiol & 0.434 & 1 \\
\hline Bull NY Acad Med & 0.370 & \\
\hline Appl Ergon & 0.356 & 1 \\
\hline f Hand Surg & 0.258 & 1 \\
\hline Aust $\mathcal{F}$ Rural Health & - & 1 \\
\hline Brf Urol & - & 1 \\
\hline Can F Public Health & - & 1 \\
\hline Int $\mathcal{F}$ Occup Med Environ Health & - & 1 \\
\hline Int $\mathcal{F}$ Paediatr Dent & - & 1 \\
\hline f Dent Hyg & - & 1 \\
\hline F Formos Med Ass & - & 1 \\
\hline f Korean Med Sci & - & 1 \\
\hline f Pak Med Assoc & - & 1 \\
\hline Kao Hsuing I Hsueh Ko Hsueh Tsa Chich & - & 1 \\
\hline Med Confl Surviv & - & 1 \\
\hline Med Tr Prom Ekol & - & 1 \\
\hline Monaldi Arch Chest Dis & - & 1 \\
\hline Orv Hetil & - & 1 \\
\hline SAR QSAR Environ Res & - & 1 \\
\hline Southeast Asian $\mathcal{F}$ Trop Med Public Health & - & 1 \\
\hline
\end{tabular}

for a $10 \%$ random sample (350 articles) of manuscripts rejected in 1993-4 from the Annals of Internal Medicine, ${ }^{1}$ but it is similar to that recently obtained for Cardiovascular Research, where $47 \%$ of all the 644 manuscripts rejected in 1995-6 could be traced. ${ }^{2}$ In older studies, subsequent publication rates have ranged between $38 \%$ and $85 \%$, as summarised by Ray et $a l .{ }^{1}$ It is likely that more articles were published than reported here, in journals with a more local distribution and in other languages, which are not covered by Medline. Thus, in a study of 108 articles rejected in 1992 from the Nederlands Tijdschrift voor $\mathrm{Ge}$ neeskunde (Dutch Medical Journal), only 14 were traced through Medline within 2 years, but a questionnaire showed that a substantial proportion (49\%) of the articles had been published in journals not covered by Medline (of which $40 \%$ were in English). ${ }^{3}$

Most articles rejected by OEM were published elsewhere within 2 to 3 years of being rejected and this is similar to figures obtained elsewhere. Thus, after rejection by the Annals of Internal Medicine most articles appeared within 2.5 years and the mean latency was 552 days (range 121 to 1792 days). ${ }^{1}$

In general, articles rejected by $O E M$ were published in journals with a similar scopethat is, journals covering the broad field of occupational and environmental healthrather than in specialist journals dealing with - for example, pneumology or neurology. This seems to be opposite to the experience of general medical journals, such as the Annals of Internal Medicine, ${ }^{1}$ where most manuscripts are subsequently published in specialty journals (it is probable that occupational medicine is itself considered as a specialty).

Most $(90 \%)$ of the rejected articles were eventually published in journals with an impact factor below that of OEM, and this too is comparable with the findings of other studies. ${ }^{12}$ The papers rejected by the Annals of Internal Medicine (average impact factor of 9.60 in 1993-4) were eventually published in journals with a mean impact factor of $3.09,{ }^{1}$ and those rejected by Cardiovascular Research (impact factor of 2.88 to 3.26 in 1996-8) were eventually published in journals with an average impact factor of $1.64 .^{2}$ The impact factor is a bibliometric indicator that reflects the average number of citations received by the average article of a journal per year. It is the most commonly used, but also the most misused measure derived from the citation curve of a journal. ${ }^{4}$ Impact factors depend on subject area and on the size and type of the journal, they fluctuate from year to year, and they are not necessarily good reflections of quality. Thus the impact factor of $O E M$ is quite low (1.96) when compared with many biomedical journals, but it has the highest impact factor of the journals publishing original research in occupational health.

It is difficult with the present material to draw very strong conclusions about the preferences of authors to publish in a particular journal according to their origin. Nevertheless the data from table 3 do give some clues. As in OEM, the American Fournal of Industrial Medicine seems to draw from an international audience with only four papers from the USA and four from Canada. The other journals seem to attract authors from more specific geographical areas. Thus, the International Archives of Occupational and Environmental Health, originally a 
Table 3 Geographical origin of papers published in major journals after rejection by OEM

\begin{tabular}{lrrrcccc}
\hline & AfIM & IAOEH & OccMed & SfWEH & fOEM & AEH & IndHealth \\
\hline USA + Canada & 8 & 1 & 1 & 0 & 8 & 7 & 0 \\
Europe (+ Israel) & 18 & 14 & 10 & 11 & 5 & 4 & 0 \\
$\quad 7$ & 4 & 1 & 7 & 1 & 3 & 0 \\
Nordic & 7 & 1 & 5 & 0 & 0 & 0 & 0 \\
United Kingdom & 0 & 8 & 4 & 4 & 4 & 1 & 0 \\
Other & 11 & 5 & 3 & 3 & 1 & 1 & 10 \\
Asia + Australia & 3 & 1 & 0 & 0 & 0 & 0 \\
Other & 1 & 0 & 1 & 14 & 14 & 12 & 10 \\
Total & 30 & 20 & 15 & &
\end{tabular}

AfIM=Am $f$ Ind Med; IAOEH=Int Arch Occup Environ Health; OccMed=Occup Med;

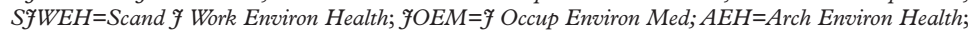
IndHealth=Ind Health.
It would be interesting to evaluate now the trajectory of the papers that did get published in OEM. How many of them were first submissions? How many were second choices after rejection by specialist journals, which generally have higher impact factors? How many had been first rejected by direct competitors of $O E M$ ? Such a study would be fairly easy to perform by asking the authors of already published papers to respond, either anonymously or not, to a brief questionnaire about the history of their article. Such information would allow us to assess more objectively than with bibliometric indices, the relative quality and prestige of $O E M$ in the area of occupational and environmental health research and this would probably be useful not only for the editors and publisher of OEM, but also for the fournal's readership and potential authors.

dinavian Fournal of Work and Environmental Health publishes more articles from the Nordic countries; the Fournal of Occupational and Environmental Health and the Archives of Environmental Health, both published in the United States, have the highest relative proportions of authors from the United States; all papers in Industrial Health, published by Japan's Institute of Industrial Health, come from Japan, Taiwan, or South Korea.

Because the affiliation of the authors was not mentioned on the list of rejected papers, it was not possible to analyse whether the geographical origin of a rejected paper influenced the likelihood of it still being published in the end, but one has the impression that articles that presumably originate from third world countries are more easily lost.
I thank Ms $\mathrm{H}$ Vanhooren for her help in retrieving articles. BN is a member of the editorial board of $O E M$, but this article was reviewed by an anonymous reviewer, who provided useful sugreviewed by an anonym
gestions to improve it.

1 Ray J, Berkwits M, Davidoff F. The fate of manuscripts rejected by a general medical journal. $\mathrm{Am} \mathscr{f} \mathrm{Med}$ 2000;109:131-5.

2 Opthof T, Furstner F, van Geer M, et al. Regrets or no regrets? No regrets! The fate of rejected manuscripts. Cardiovasc Res 2000;45:255-8.

3 Koene HR, Overbeke AJ. De uiteindelijke bestemming van artikelen afgewezen voor publikatie in het Nederlands Tijdschrift voor Geneeskunde (The ultimate fate of articles rejected for publication in the Nederlands Tijdschrift voor Geneeskunde). Ned Tijdschr Geneeskd 1994;138:2443-6.

4 Amin M, Mabe M. Impact factors: use and abuse. Perspectives in Publishing 2000;1-6. (http:// www.elsevier.com/homepage/about/ita/editors/ perspectives 1.pdf)

\section{1st Asia Pacific Forum on Quality Improvement in Health Care. Three day conference Wednesday 19 to Friday 21 September 2001
Sydney, Australia}

We are delighted to announce this forthcoming conference in Sydney.

Delegate enquiries are welcome.

The themes of the Forum are:

- Improving patient safety

- Leadership for improvement

- Consumers driving change

- Building capacity for change: measurement, education, and human resources

- The context: incentives and barriers for change

- Improving health systems

- The evidence and scientific basis for quality improvement.

Presented to you by the BMJ Publishing Group (London, UK) and Institute for Healthcare Improvement (Boston, USA), with the support of the the Commonweatlh Department of Health and Aged Care (Australia), Safety and Quality Council (Australia), NSW Health (Australia), and Ministry of Health (New Zealand).

For more information contact: quality@bma.org.uk or fax +44 (0) 73836869 